$\mathbb{T}$ periodica polytechnica

Civil Engineering

58/1 (2014) 87 92

doi: 10.3311/PPci.7409

http://periodicapolytechnica.org/ci

Creative Commons Attribution (1)

RESEARCH ARTICLE

\section{Affection radii of congested junctions on traffic networks}

\author{
Gergely Vasvári
}

Received 2013-01-18, revised 2013-02-18, accepted 2013-03-05

\begin{abstract}
The article investigates the spatial effects of traffic congestion. Three and four legged rural road intersection are analyzed, regarding single and double through lanes. The analysis is based on momentary individual vehicle speeds, but other flow parameters are taken into account as well. Values are determined by ways of microsimulation, results are given in both directions of the junction for the major flow, the effects on minor flows are not evaluated.
\end{abstract}

\author{
Keywords \\ congestion $\cdot$ junction $\cdot$ intersection $\cdot$ affection radius $\cdot$ mi- \\ crosimulation $\cdot$ VISSIM
}

\section{Introduction}

This paper details a preliminary research which establishes preferable values of junction spacing based on junction type and geometry. These values will be used later to create a model of a junction series where superposed volume delay function [1] parameters would be determined.

To enable differentiation between the case of unaffected traffic flow at a junction and situations where neighboring junctions are affecting each other, an examination was carried out. The assessment of the distance where a congestion caused by a traffic junction has effect (affection radius, $R_{\mathrm{A}}$ ) is presented in the following paragraphs.

Conventional flow and capacity theories $[2-5]$ do not focus on events near or beyond the congested state as the scope of these theories is to predict a level of service for different junction geometries and vehicle volumes, and estimate certain characteristics of the traffic flow. Their goal is to set the limits of acceptable service, which keeps clear of the congested state. Although there are existing methods for predicting flow parameters under traffic congestion [6], the affection radius is a requisite of the junction series' microsimulation so it is logical to determine its value through the same application - VISSIM [7,8] in this case.

\section{Temporal range}

A steady high volume of traffic results in ever growing vehicle queues over time, thus $R_{\mathrm{A}}$ would approach infinity. Also in real life, high volumes of vehicle traffic do not last forever, their usual occurrence is in peaks. The so called peak hour traffic flow has the shape of an inverted parabola. It is favorable to adjust the vehicle inputs to have similar shape to a peak period, but as vehicle arrivals are stochastic, it is unreasonable to strictly follow the parabolic curve. To determine an average length of the peak period, and its ascending and descending characteristics, traffic flow data were analyzed from a previous series of measurements (BME, 2008). The previous assessment took place in Pest County, Hungary and consist data from 12 sites over a 6 day (five work days and one day of the weekend) period. The sites are regular road intersections in semi-rural environments. Data was collected in 15 minutes intervals, with differentiation of 12
Department of Highway and Railway Engineering, Budapest University of Technology and Economics, Múegyetem rkp. 3, H-1111 Budapest, Hungary e-mail: vasvari@uvt.bme.hu 
vehicle classes. Significant peak periods were selected from the measurements, and the values were converted to passenger car units (pcu), a rolling sum of four periods (one hour) was calculated, then the calculated values were normalized to provide an isomorphic base for analysis. The morning and afternoon periods were separated due to their different shape. On Figure 1 only normalized graphs are displayed to show similarities of peak periods. The values in 6-12h and $13-22 \mathrm{~h}$ ranges are from different measurement days or sites.

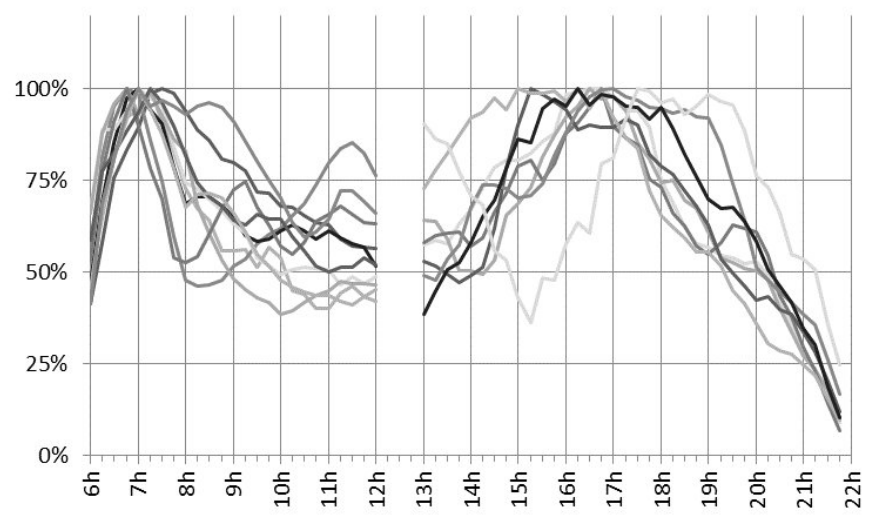

Fig. 1. Normalized measurement data

It is apparent that the peak period can be divided into three phases as was expected earlier. Regarding the congested state the sustained length of the peak is its most important attribute.

Averages of total and sustained peak time of the period are shown on Figure 2, displaying traffic flows in absolute (passenger car unit per hour) and normalized (percentage) values.

\begin{tabular}{|c|c|c|c|c|c|c|c|}
\hline \multirow{2}{*}{$\begin{array}{l}\text { loca } \\
\text { tion }\end{array}$} & \multirow{2}{*}{$\begin{array}{c}\text { mea } \\
\text { sure } \\
\text { ment }\end{array}$} & \multicolumn{2}{|c|}{$\begin{array}{c}\text { range } \\
\text { [h] }\end{array}$} & \multicolumn{4}{|c|}{$\begin{array}{c}\text { traffic flow } \\
\text { [pcu/h] }\end{array}$} \\
\hline & & $\begin{array}{l}\text { total } \\
\text { time }\end{array}$ & $\begin{array}{l}\text { sust. } \\
\text { time }\end{array}$ & nom & & & $a k$ \\
\hline \multicolumn{8}{|c|}{ Morning } \\
\hline \multicolumn{2}{|c|}{ Average } & 2,9 & 0,70 & 486 & $58 \%$ & 830 & $100 \%$ \\
\hline Site 1 & 2 & 2,5 & 0,50 & 785 & $82 \%$ & 960 & $100 \%$ \\
\hline \multirow{3}{*}{ Site 3} & 1 & 2,0 & 0,75 & 435 & $56 \%$ & 779 & $100 \%$ \\
\hline & 2 & 2,0 & 0,50 & 336 & $47 \%$ & 713 & $100 \%$ \\
\hline & 4 & 2,0 & 0,50 & 542 & $69 \%$ & 788 & $100 \%$ \\
\hline \multirow{3}{*}{ Site 4} & 1 & 4,0 & 1,00 & 389 & $51 \%$ & 765 & $100 \%$ \\
\hline & 2 & 3,5 & 1,00 & 289 & $43 \%$ & 665 & $100 \%$ \\
\hline & 3 & 1,5 & 0,25 & 316 & $54 \%$ & 586 & $100 \%$ \\
\hline \multirow{3}{*}{ Site 9} & 1 & 3,0 & 0,25 & 643 & $67 \%$ & 960 & $100 \%$ \\
\hline & 2 & 4,0 & 0,25 & 543 & $48 \%$ & 1137 & $100 \%$ \\
\hline & 4 & 4,5 & 2,00 & 578 & $61 \%$ & 950 & $100 \%$ \\
\hline \multicolumn{8}{|c|}{ Afternoon } \\
\hline \multicolumn{2}{|c|}{ Average } & 5,8 & 1,64 & 356 & $52 \%$ & 686 & $100 \%$ \\
\hline \begin{tabular}{|l|} 
Site 1 \\
\end{tabular} & 4 & 5,0 & 1,00 & 545 & $59 \%$ & 920 & $100 \%$ \\
\hline \multirow{3}{*}{ Site 3} & 2 & 6,0 & 1,00 & 322 & $56 \%$ & 579 & $100 \%$ \\
\hline & 3 & 5,0 & 0,25 & 416 & $57 \%$ & 727 & $100 \%$ \\
\hline & 4 & 5,0 & 1,00 & 344 & $48 \%$ & 715 & $100 \%$ \\
\hline \multirow{3}{*}{ Site 4} & 1 & 6,0 & 3,00 & 356 & $49 \%$ & 728 & $100 \%$ \\
\hline & 2 & 6,0 & 2,50 & 343 & $61 \%$ & 562 & $100 \%$ \\
\hline & 3 & 8,0 & 3,00 & 305 & $41 \%$ & 736 & $100 \%$ \\
\hline \multirow{2}{*}{ Site 9} & 1 & 5,0 & 1,00 & 337 & $59 \%$ & 571 & $100 \%$ \\
\hline & 3 & 6,0 & 2,00 & 234 & $37 \%$ & 640 & $100 \%$ \\
\hline
\end{tabular}

Fig. 2. Details of peak hour characteristics

While the afternoon peak period is considerably longer than the morning peak, it also has lower count of vehicles, which decreases its significance. Thus the morning period was incorporated to the simulation models.

According to these values, the peak period's length was set to 45 minutes, with 60 minutes long ascending and 75 minutes long descending phase for a total length of 3 hours. The starting and ending volume values are $58 \%$ of the peak volume.

\section{Spatial extents}

The network segment inside the simulation model has to be large enough to contain the congestion so its boundaries could be measured. The model size has immediate effect on the maximum speed of simulation therefore it should not be set to an unreasonable size. The first estimate of $5 \mathrm{~km}$ network length on either side of the junctions proved to be insufficient, and was increased to $20 \mathrm{~km}$.

\section{Modeling considerations}

Several aspects of the simulation method [9] were analyzed by exploratory simulations. The results of those simulations are presented here along with general assumptions.

\subsection{Traffic volume}

It could be assumed that the build-up phase of the peak vehicle volume may be omitted as it has no influence on the congested state. To confirm this assumption the junction models were analyzed to the full extent of the peak period. The receding phase however has a significant effect on the dissipation rate of vehicle queues and by that the affection radius itself, therefore it must be considered in the microsimulation models. Values of traffic volume were set according to Figure 3. The $100 \%$ ratio represents the analyzed value of the peak period, whereas lower ratios indicating proportionate volumes of the peak. Ratios and time spans were derived from the results displayed on Figure 2. Considering the length of the network, a 1200 seconds long warm up period was included in the simulation.

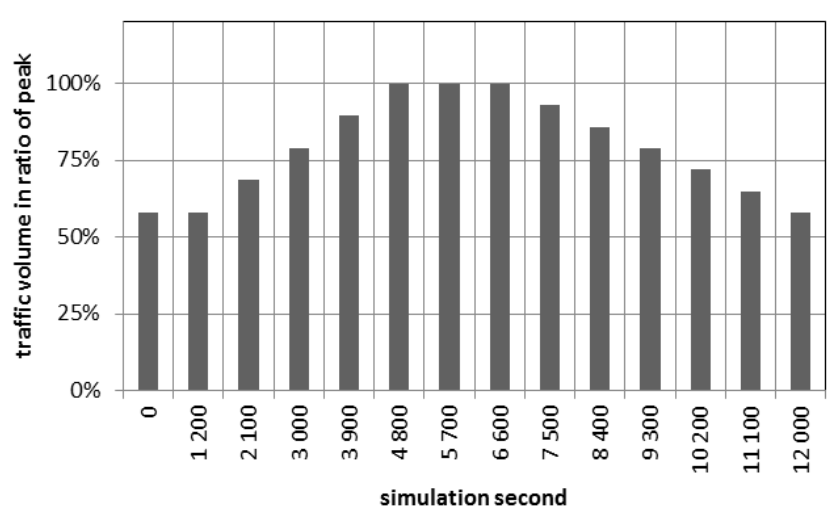

Fig. 3. Traffic volume ratios

\subsection{Model size}

The dimension of the network model may be restrained by the modeling application itself as microsimulation models are often consisting only a limited part of a larger network and analyzing a road section of greater length is not the purpose of these applications. The modeling area in VISSIM is defined by a 'bounding 
box' which is a straight square consisting the whole traffic network in the model. After inspecting a few simulation results it was clear that simply stretching a straight line of road to the limits of the model area is not enough to contain the whole of the congestion. The upstream and downstream parts of the network had to be lengthened by 'winding up' the links at the extents (see Figure 4) which implied the 'unwinding' transformation of the resulting spatial vehicle records.

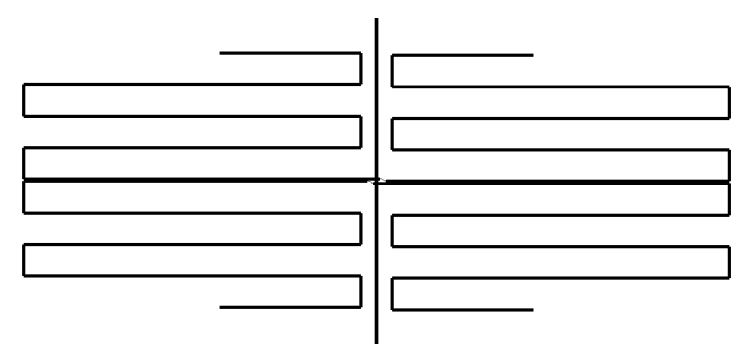

Fig. 4. Long road sections in confined model space

\subsection{Data collection, evaluation}

Determining a dynamic variable such as the range of the congested traffic flow [10] requires spatially extensive data acquisition with adequate resolution in time. Characteristics of the traffic flow can be measured point-wise by defining data collection points at various distances along the network and gathering attributes of passing vehicles over a time. Or they can be measured sequentially by recording every vehicle position and attribute at various time intervals and deriving spatial distribution of the selected attributes afterwards. While the first method requires the definition of numerous measurement sections, the results are com-pact. The second method produces a wealth of information which makes it more accurate but also renders analysis elaborate. A comparison between the two methods (Figure 5 and Figure 6] shows that the later one is preferable as it allows to firmly locate the spatial limits of a congestion (which covers the entire inspection area on the figure). Note that the results displayed on Figure 5 and Figure 6 are from early tests, being flawed spatially, as the model was not large enough to contain all of the congestion.

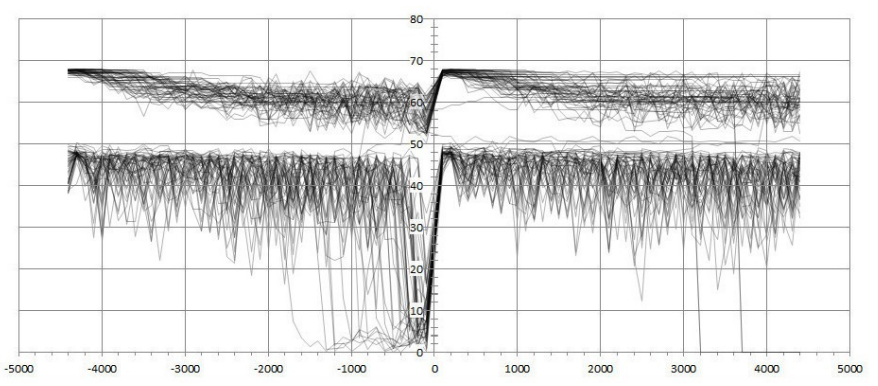

Fig. 5. Minimum and maximum speeds measured at $100 \mathrm{~m}$ intervals, by 300 s over $3600 \mathrm{~s}$ simulation

Preliminary tests confirmed that a sampling rate of $0,1 \mathrm{~Hz}$ (one sample per ten seconds) adequately records vehicular data and have inconspicuous difference compared to $10 \mathrm{~Hz}$ or $1 \mathrm{~Hz}$ sampling rate.

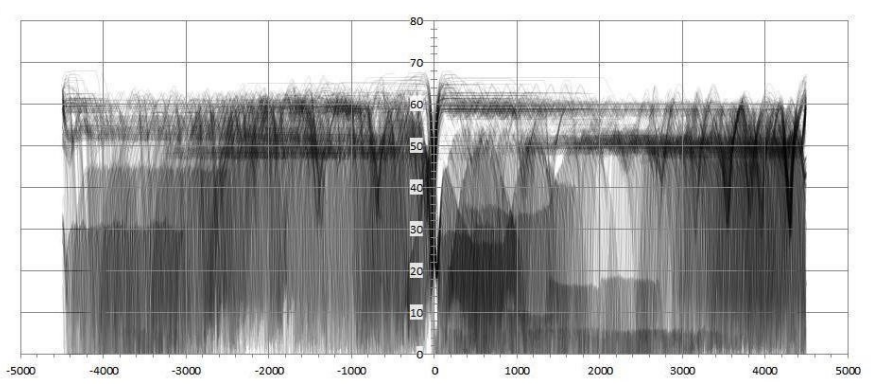

Fig. 6. Speed graphs based on vehicle records of the last $300 \mathrm{~s}$ interval of the simulation

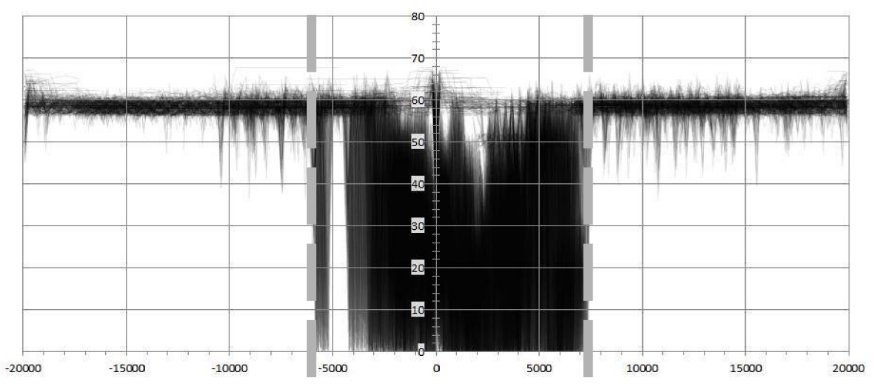

Fig. 7. Typical momentary speed graph of a 4 legged junction

Boundaries of the congested network could be deduced from the inspection of different momentary attributes directly. Speed, travel time, headway and acceleration values were examined to select the most suitable parameter for the task or to confirm the need of derived variables as density, or occupancy [4]. The following graphs show that either primary attribute is sufficient although the changes in speed are the most significant - and there is no need for the calculation of derived variables.

On Figure 7 momentary values in time are arranged and connected per vehicle. The first graph shows momentary vehicle speeds. A small spread around the speed limit $(60 \mathrm{~km} / \mathrm{h})$ indicates that vehicle movement is unaffected by other vehicles. The vertically widening section implies smaller disturbances in the flow, while sudden drops and rises (the dense area of the graph) are the signs of higher turbulences e.g. congested state.

The same conclusion could be deduced from other symptoms. The steeply rising cluster of travel time curves (Figure 8) indicating slower movements. The higher density of the cluster is the result of increasing flow density.

Although the high deviance in headway in uncongested state is not so apparent at first glance on Figure 9, the drop of distance between vehicles is perceptible.

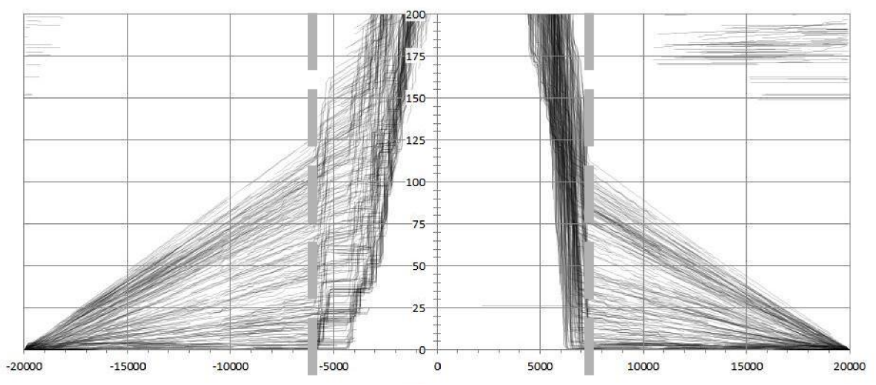

Fig. 8. Typical momentary travel time of a 4 legged junction 


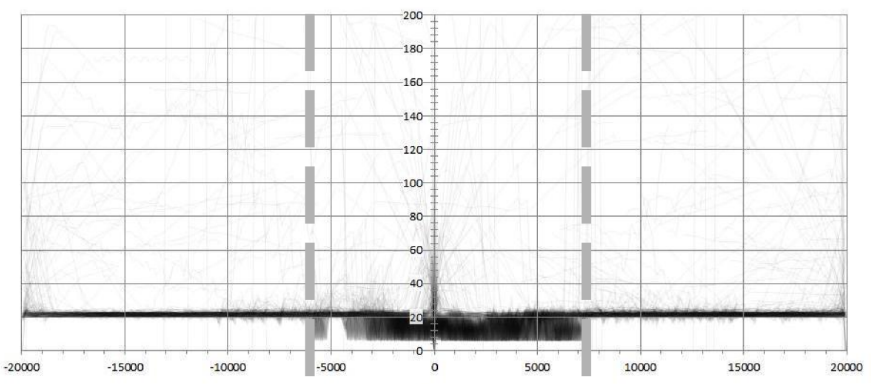

Fig. 9. Typical momentary headway of a 4 legged junction

Congestion is also highly probable according to the great spread of acceleration values (Figure 10), which is the result of repetitive braking and accelerating.

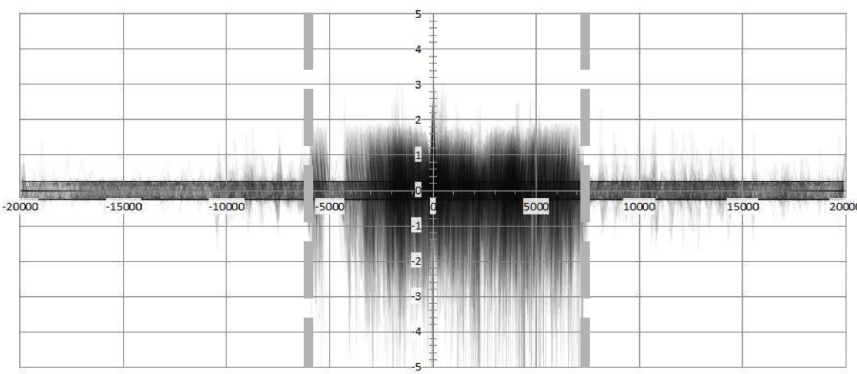

Fig. 10. Typical momentary acceleration of a 4 legged junction

Dividing the records into time-slices makes it more comprehensible and also allows observation of the dynamics of the congestion: a temporally arranged set of visualized momentary speed graphs shows the oscillation of the congestion boundary and its dissipation in time. The span of these intervals was set to 5 minutes ( 300 seconds) by practical considerations: the amount vehicle records over the $40 \mathrm{~km}$ length of the examined network are manageable while the number of intervals stays synoptic.

Considering the length of the network, vehicles have to travel for 20 minutes to approach the intersection, thus results from 0 to 1200 seconds were discarded

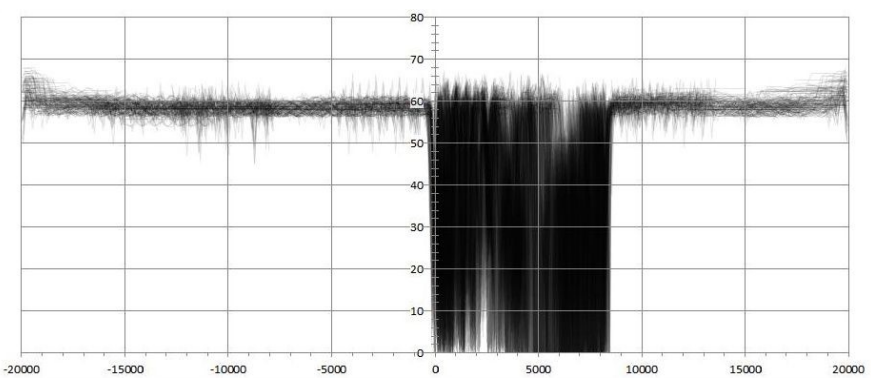

Fig. 11. Typical speed graph of a 3 legged junction

\section{Results}

A typical vehicle speed graph is shown on Figure 11 displaying an affection radius of $1300 \mathrm{~m}$ to the left, and $200 \mathrm{~m}$ to the right. It should be noted that the value of $R_{\mathrm{A}}$ cannot be determined by a single graph of 300 second interval, since the boundaries of the congestion are constantly moving, oscillating around the junction. It is necessary to examine the whole set of graphs to set the limits in which vehicle queues are contained, and also to confirm, that the congestion began to dissolve around the end of the simulation. A steady or growing range of congested state would indicate inadequately short simulation time span or that the model did not really contain the whole congestion (see Figure 6). Such faults were not detected after the final set of simulations.

The examination of every speed graph on four different types of intersections yields to the following affection radii:

\begin{tabular}{|cc|r|r|}
\hline intersection type & $\mathbf{R}_{\mathrm{A}}$ left & $\mathbf{R}_{\mathrm{A}}$ right \\
\hline \multirow{2}{*}{3 legs } & $\begin{array}{l}\text { 1 through lane } \\
\text { 2 through lanes }\end{array}$ & 4500 & 8600 \\
\cline { 3 - 4 } & 600 & 4100 \\
\hline \multirow{2}{*}{4 legs } & $\begin{array}{l}\text { 1 through lane } \\
\text { 2 through lanes }\end{array}$ & 13000 & 10500 \\
\cline { 2 - 4 } & 1400 & 1700 \\
\hline
\end{tabular}

Fig. 12. Affection radii of different junction types

It is important to note the bipolar nature of three legged junctions: under high traffic volume, the major flow with a left turn suffers a significant amount of delay with increasing vehicle queues, while the opposing major flow (with right turn) may be relatively undisturbed. Due to this behavior the orientation of this junction type cannot be disregarded in the application of $R_{\mathrm{A}}$.

\section{Analogies}

To have better judgment of the results, it is necessary to examine the values from another perspective.

Maximum queue lengths were calculated for two existing standards on tolerable service levels to provide a sufficient base for comparison.

\subsection{Hungarian standard (UME)}

The Hungarian standard [2] sets six levels of service, labeled from LOS-A to LOS-F, 'A' being the best, 'F' being the worst. The levels are determined by readings (Figure 13) of average waiting time $\left(t_{\mathrm{v}}\right)$, which is the function of prioritized (designated variable is also $F$ ) and yielding $\left(f_{\mathrm{m}}\right)$ flows. Note that $f_{\mathrm{m}}$ values greater than 500 are disregarded as they usually cause intolerable traffic situations.

The category of the worst level of service (LOS-F) has only a lower limit, meaning that traffic flow with waiting time values beyond that limit $\left(t_{\mathrm{v}}=90 \mathrm{~s}\right)$ are considered to be congested, thus providing unacceptable service. It is logical to investigate queue lengths related to this $t_{\mathrm{v}}$ value, as it is also the higher limit of the last accepted level of service (LOS-E).

Calculation of queue length involves the reading the average number of waiting vehicles on a similar graph and determining a coefficient which multiplies the read value to a standardized number of waiting vehicles. Queue length is then:

$$
L=N_{m} \cdot 6[\mathrm{~m}]
$$

where: 
$N_{m}=N \cdot b:$ standardized number of waiting vehicles

$N$ : average number of waiting vehicles

$b$ : standard coefficient

Examining Figure 13 it is apparent that there are two extremes of $t_{\mathrm{v}}=90 \mathrm{~s}$. One is at $\left(F=650 ; f_{\mathrm{m}}=500\right)$, other is as $(F=1350$, $\left.f_{\mathrm{m}}=200\right)$. Calculation of queue lengths for the two pair of values gives the result of 162 and 60 meters.

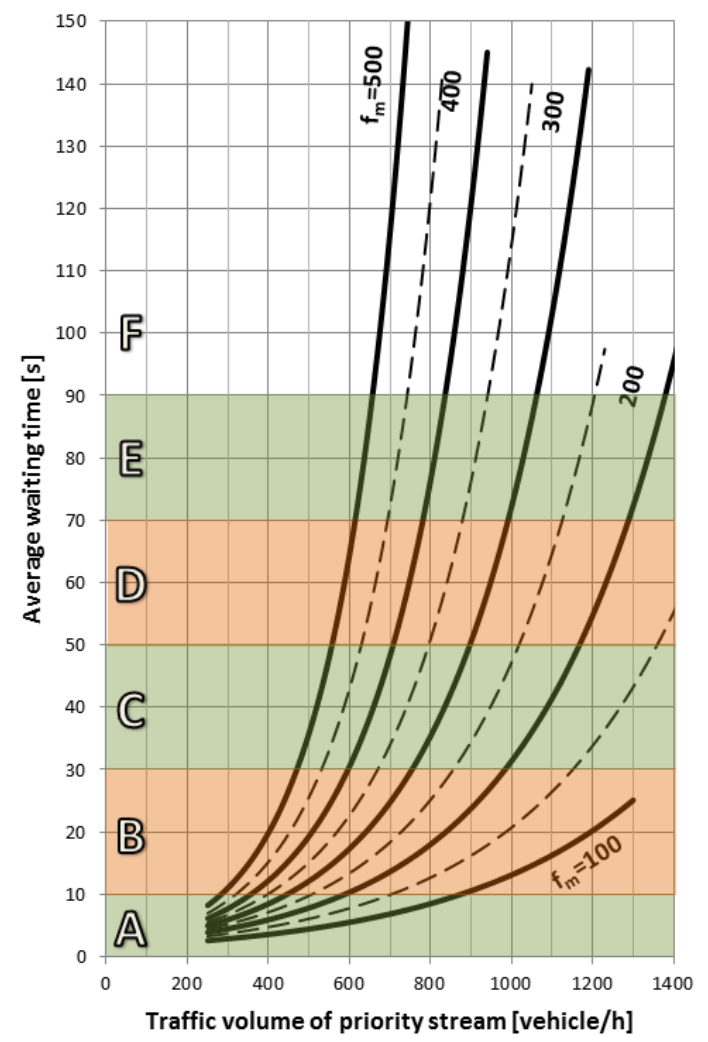

Fig. 13. Average waiting time, Hungarian standard (reproduced by the author)

\subsection{US standard (HCM)}

In the Highway Capacity Manual (HCM) levels of service are categorized by control delay, from LOS-A to LOS-F, parallel to the Hungarian standard (its categorization was partially derived from HCM).

While the method described in HCM is very elaborate, it has the means to give estimated queue lengths for arbitrary volume and capacity ratios and is not limited by a range of empirical graphs which do not give information beyond their scope.

As computational steps of intermediate values are numerous only the critical equations are displayed here.

The $95^{\text {th }}$ percentile queue length's value (number of vehicles) for two-way stop-controlled (TWSC) intersections is calculated directly without deducting values from other context:

$Q_{95} \approx 900 \cdot T \cdot\left[V R-1+\sqrt{(V R-1)^{2}+\frac{\left(\frac{3600}{c_{m, x}}\right) \cdot V R}{150 \cdot T}}\right] \cdot\left(\frac{c_{m, x}}{3600}\right)$

where:
$V R=\frac{v_{x}}{c_{m, x}}:$ volume ratio

$v_{x}$ : flow rate for movement $x(\mathrm{veh} / \mathrm{h})$

$c_{m, x}$ : capacity of movement $x(\mathrm{veh} / \mathrm{h})$

$T$ : analysis time period (h)

Although the control type of the method is not equal to the control type in the simulation models (which is two way yield), it is reasonable to compare determined queue lengths to the simulation results, as the examined flows in the current calculation are the major flow's left turns, which are not required to stop before yielding on TWSC junctions either. Minor flows are not analyzed here.

However the $95^{\text {th }}$ percentile queue length does not account for the effects of an oversaturated left turn lane, where the waiting vehicles are blocking the way of the through lane. Therefore it is also useful to calculate average queue lengths based on average delay times, where the probability of lane blocking does take effect. Average queue length is the product of average delay per vehicle and flow rate:

$$
\bar{Q}_{x}=\frac{d_{x}}{3600} \cdot v_{x}
$$

where:

$d_{x}=\frac{3600}{c_{m, x}}+900 \cdot T \cdot\left[V R-1+\sqrt{(V R-1)^{2}+\frac{\left(\frac{3600}{c_{m, x}}\right) \cdot V R}{450 \cdot T}}\right]+5$

(other terms are previously defined)

Results of the calculations are shown or Figure 14

\begin{tabular}{|cc|r|r|}
\hline \multicolumn{2}{|c|}{ intersection type } & \multicolumn{1}{c|}{$\boldsymbol{Q}_{\mathbf{9 5}}$} & \multicolumn{1}{c|}{$\overline{\boldsymbol{Q}}$} \\
\hline \multirow{2}{*}{ 3 legs } & $\begin{array}{l}\text { 1 through lane } \\
\text { 2 through lanes }\end{array}$ & 3051 & 22233 \\
\cline { 3 - 4 } & 4 327 & 12589 \\
\hline \multirow{2}{*}{ legs } & $\begin{array}{l}\text { 1 through lane } \\
\text { 2 through lanes }\end{array}$ & 2752 & 13627 \\
\cline { 3 - 4 } & 4 965 & 2722 \\
\hline
\end{tabular}

Fig. 14. Queue lengths according to HCM 2010

\section{Conclusions}

According to measurements in Pest County, the temporal course of a typical peak period was determined, as a 3 hours long time span with a sustained peak over 45 minutes, where the highest volumes are $72 \%$ higher than the lowest values. The spatial limits of the congestion caused by 45 minutes long peak period were determined for the examined junction types. The results confirmed the known phenomena of disproportionate difference between single and two lane junctions of the same type. These values help to determine the spacing of various junction types in a single microsimulation model where the analysis of superposed volume delay function parameters would be elaborated.

Through the tests it was also confirmed, that inclusion of the ascending flow volumes does not have any effect on the results. The longest queues were found during the highest traffic volumes, as it was expected. It is worth to note the time offset which 
is needed for the oncoming vehicles to reach the examined intersection, as queue discharge can only be expected past the point in time where the peak flow reaches the junction. It also denotes the beginning development of extensive congestion, but the longest queues may appear only one hour after the highest volume enters the model.

Analogies with current capacity theories' queue length values show similarities only in case of the HCM calculations. Although it is laid down in both standards that the methodologies do not apply or have highly reduced accuracy under highly saturated traffic flows, most of the HCM's results have the same order of magnitude as the result of the simulation However, comparison of discrete result show opposing tendencies of queue length regarding $95^{\text {th }}$ percentile and average values. The explanation is in the calculation steps of the two lengths:

$Q_{95}$ is proportional to ratio of turning volume and movement capacity $\left(v_{\mathrm{x}} / c_{\mathrm{m}, \mathrm{x}}\right)$, where the latter is the function of the conflicting flow. As the conflicting flow rises (two lane carries more vehicles), movement capacity reduces, and the ratio of $v_{\mathrm{x}} / c_{\mathrm{m}, \mathrm{x}}$ grows, heightening the queue length. The process is logical, since $Q_{95}$ is determined only for the turning lane.

Regarding this phenomena in the examined congested state it is more reasonable to consider the average queue length, which value is based on the probability of overflowing left turn lane and the traffic volume on the neighboring through lane. Although the determined values of average queue length is not always close to the simulated values, the ratios of single and double through lane configuration's queue lengths of calculated and simulated results are close to each other.

\section{Further research}

As the determined values of the affection radius are to be used in the analysis of chained junctions' volume delay function parameters the validation to real life measurements [11] was unnecessary, although - once validated the method demonstrated here shows the potential to assess valuable information for engineering practice [12,13]. Widening the analysis to determine affection radii in context of vehicle volume and establishing the definition of quality (Level of Service) according to the distance between typical junction types is a logical extension of the subject.

\section{References}

1 Ortúzar JdD, Willumsen LG, Modelling Transport, 4th edition, John Wiley \& Sons, Ltd.; United Kingdom, 2011, DOI 10.1002/9781119993308

2 Szintbeni közúti csomópontok méretezése és tervezése ,ÚT 2-1.214 (in hungarian), MAÚT; Budapest, Hungary, 2004.

3 Highway Capacity Manual, Transportation Research Board; Washington DC, 2000 and 2010.

4 Hall FL, Traffic Stream Characteristics, In: Gartner DN, Messer DCJ, Rathi DAK (eds.), Traffic Flow Theory - A State-of-the-Art Report, US Department of Transport, Federal Highway Administration, 2001, pp. 2-1-2-37.

5 Troutbeck RJ, Brilon W, Unsignalized Intersection Theory, In: Gartner

DN, Messer DCJ, Rathi DAK (eds.), Traffic Flow Theory - A State-of-the-
Art Report, US Department of Transport, Federal Highway Administration, 2001, pp. 8-1-8-41.

6 Kisgyörgy L, Rilett LR, Travel time prediction by advanced neural network, Periodica Polytechnica Civil Engineering, 46(1), (2002), 15-32.

7 VISSIM 5.40 User Manual, PTV AG; Karlsruhe, Germany, 2012.

8 VISSIM 5.40-04 COM Interface Manual, PTV AG; Karlsruhe, Germany, 2012.

9 Fi I, Application of traffic simulation in the design of intersection systems concerning traffic and environment, Periodica Polytechnica Civil Engineering, 40(2), (1996), 85-94.

10 Bényei A, Golarits P, Measurements to define relationship between traffic volume and traffic conditions in Hungary, Periodica Polytechnica Civil Engineering, 46(1), (2002), 83-94.

11 Fellendorf M, Vortisch P, Validation of the Microscopic Traffic Flow Model VISSIM in Different Real-World Situations, PTV AG; Karlsruhe, Germany, 2001.

12 Schuchmann G, Road network vulnerability - evaluation of measures in ranking damages and developments, Periodica Polytechnica Civil Engineering, 54(1), (2010), 61-65, DOI 10.3311/pp.ci.2010-1.07

13 Kerner BS, Optimum principle for a vehicular traffic network: minimum probability of congestion, Journal of Physics A: Mathematical and Theoretical, 44(9), (2011), 1-11, DOI 10.1088/1751-8113/44/9/092001 